\title{
Mechanical Analysis of a Hermetic Seal System for Applications in the Industry
}

\author{
${ }^{2}$ B. Julián E. Herrera, ${ }^{1}$ B. Javier Martínez, ${ }^{1} \mathrm{C}$. Felipe Corredor, ${ }^{1}$ U. Luis Rodríguez and \\ ${ }^{2}$ Robinson Jimenez-Moreno \\ ${ }^{1}$ Faculty of Basic Sciences and Engineering, University of the Llanos, Villavicencio, Colombia \\ ${ }^{2}$ Faculty of Engineering, Department of Mechatronic Engineering, \\ Nueva Granada Military University, Av cra. 11 N 101-80. Bogotá, Colombia \\ u3900256@unimilitar.edu.co
}

\begin{abstract}
When the need arises to create a hermetic system where a barrier can be generated between the exterior and the elements present inside a container, it is necessary to analyze certain mechanisms that by compressing a gasket, allow eliminating the existence of any orifice through which elements in a liquid or gaseous state can circulate. The present study focuses on explaining, analyzing and generating an algorithm that facilitates the design of a mechanism known as quick closing door with which it can graph and obtain important data. With that data, it is possible to argue the dimensions of each element that makes up the system and the minimum torque with which imminent movement occurs on the mechanism. The results reveal that, thanks to the algorithm, it is possible to characterize all the forces present in the movement. So with the help of software that calculates the efforts through a finite element analysis, it is possible to make a functional design that fits the design specifications.
\end{abstract}

$\underline{\text { Key words: } \text { Static dry friction, imminent motion, friction coefficient, stress, safety factor, specifications }}$

\section{INTRODUCTION}

If attention is paid to the wide variety of products that can be found commonly in homes, it is possible to notice that there are a large number of products that fulfill the function of containing an element and isolating it from the environment in which it is found by means of some sealing mechanism. The hermetic seal made with sealants (boat marketing), for example is a practice that expands to multiple areas of the industry. Specifically, in the food industry, High Density Polyethylene (HDPE) bags (Ram, 1997) are used to make the hermetic seal on food and thus, in this way bring the protected product to the consumer.

On the other hand, the sealing mechanism of a plastic bottle (Fig. 1a) by means of the screw system, allows to contain liquids that can be at a non-zero manometric
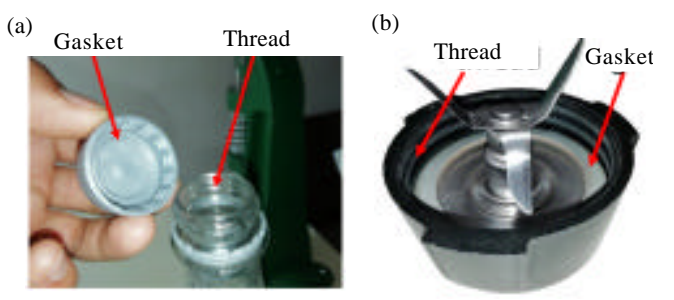

Fig. 1: a) Plastic bottle and b) Blender base pressure. Norton (2011) and Beer et al. (2013), the strings combine rotational and linear movement, allowing the cap and the mouth of the bottle to come into contact by rotation. This contact, after having generated some pressure between the elements, prevents spilling liquid. At home it can be found the same system in a blender. The base of the blender (Fig. 1b) has a thread that allows to compress a neoprene gasket that is responsible for eliminating any hole through which liquid can be spilled. This compression produces the same effect that is generated on the cap of the bottle when adjusted. Thanks to this, it is that these systems manage to contain liquids without spilling them.

Specifically, this study analyzes the sealing doors of Industrial Autoclaves (I. Autoclave) with which it is possible to carry out a process on materials that require a high exposure of pressure and temperature.

This machine is usually found with two adjustment mechanisms on the door. The difference of these lies in the way in which the gasket is compressed and then in Fig. 2-4, this difference is illustrated.

Figure 2 shows a door that has a power screw that, when rotated on its axis, allows the door to adjust and compress a gasket. This compression does not allow a slip between the surface of the door and the gasket, so, the presence of friction is only in the screw. In contrast,

Corresponding Author: B. Julián E. Herrera, Faculty of Basic Sciences and Engineering, University of the Llanos, Villavicencio, Colombia, u3900256@unimilitar.edu.co 


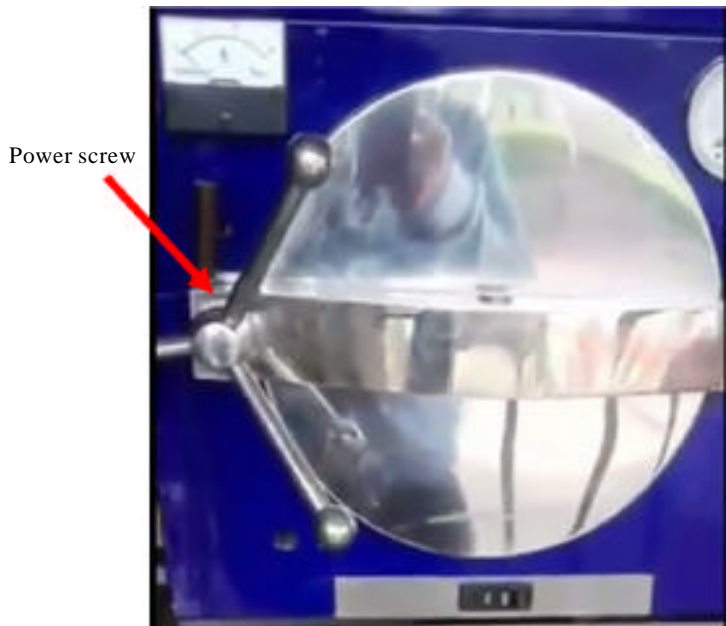

Fig. 2: Compression by power screw

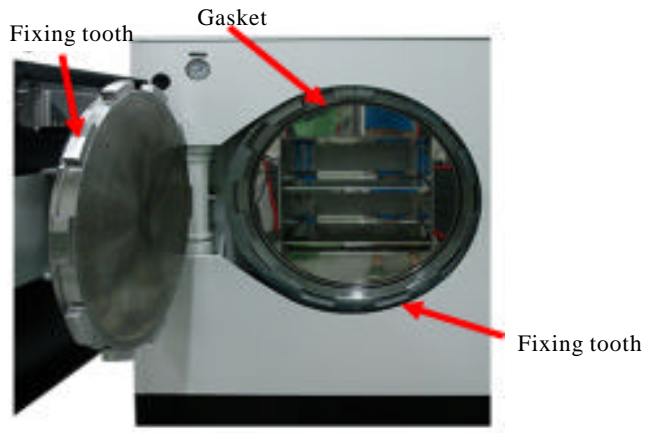

Fig. 3: Compression by quick closing door mechanism (I. Autoclave)

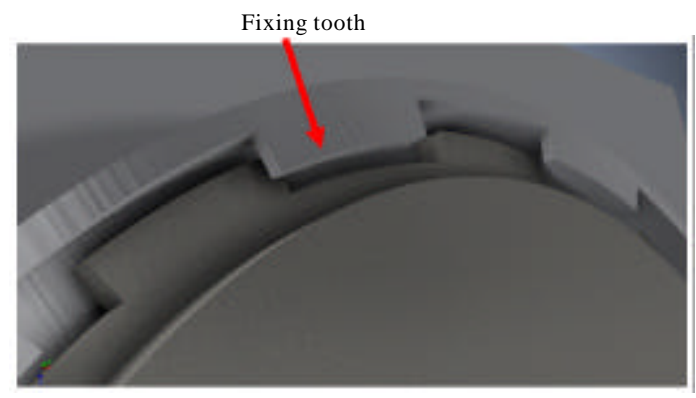

Fig. 4: Approach on the quick closing door mechanism fixing teeth

for the mechanism of Fig. 3 and 4, the compression is generated by the rotation of the door. This rotation produces friction in the gasket and the fixing teeth, causing that greater torque is required to perform the same compression. However, this mechanism is known for the speed with which it compresses the gasket which is why it is called a "quick closing door".

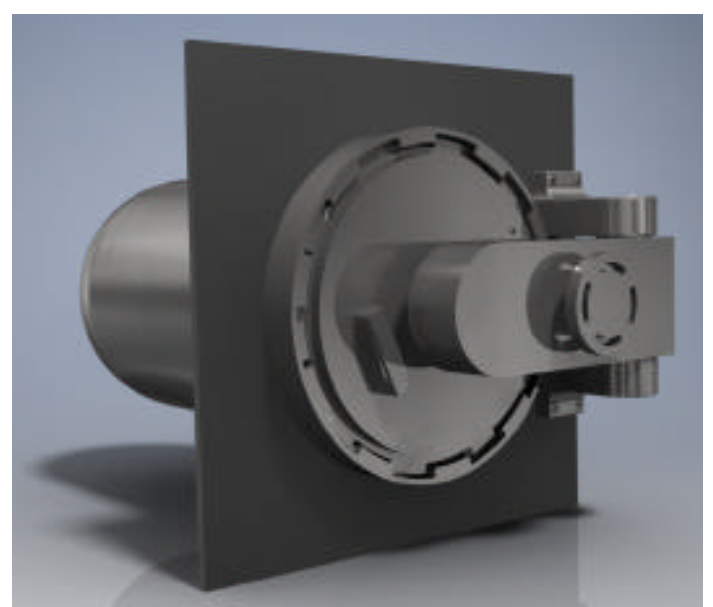

Fig. 5: Scaled model of the mechanism

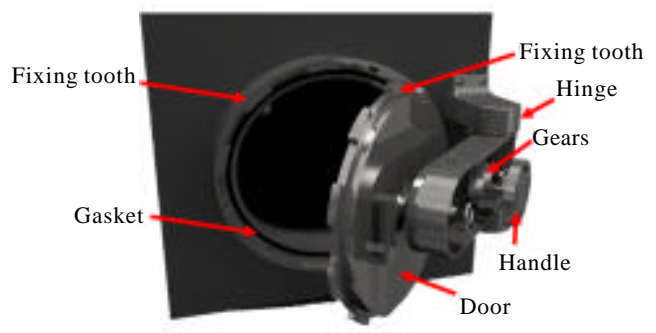

Fig. 6: Parts of the scaled model of the mechanism

The analysis performed in this study applies to the mechanism of Fig. 3 which has a door known as "Quick Closing Door" (Scholz maschinenbau) (Anonymous, 2018a-c). The objective is to explain the equations with which the system can be modeled, to apply them in an algorithm that facilitates the designers to calculate all the variables that arise when the movement of the door occurs. In this way, it is possible to reduce design times and eliminate manual calculations (Deitel and Deitel, 2012).

Static analysis: The mechanical system implemented can be seen in Fig. 5 and 6. In Fig. 6, it can be seen the most important parts of the system which are: the hinge, the door, the gears, the gasket, the handle, the fixing teeth of the camera and the fixing teeth of the door. Each part is subjected to forces that produce stress in the material which must remain below the limit of durability to fatigue implemented or if desired and the material allows it, below the limit of resistance to fatigue to achieve an infinite life on it, i.e., it is possible to achieve that the pieces never reach the failure even when they experience a load for an infinite number of cycles. This means that it is important to know the efforts on the material, so, the need arises to 


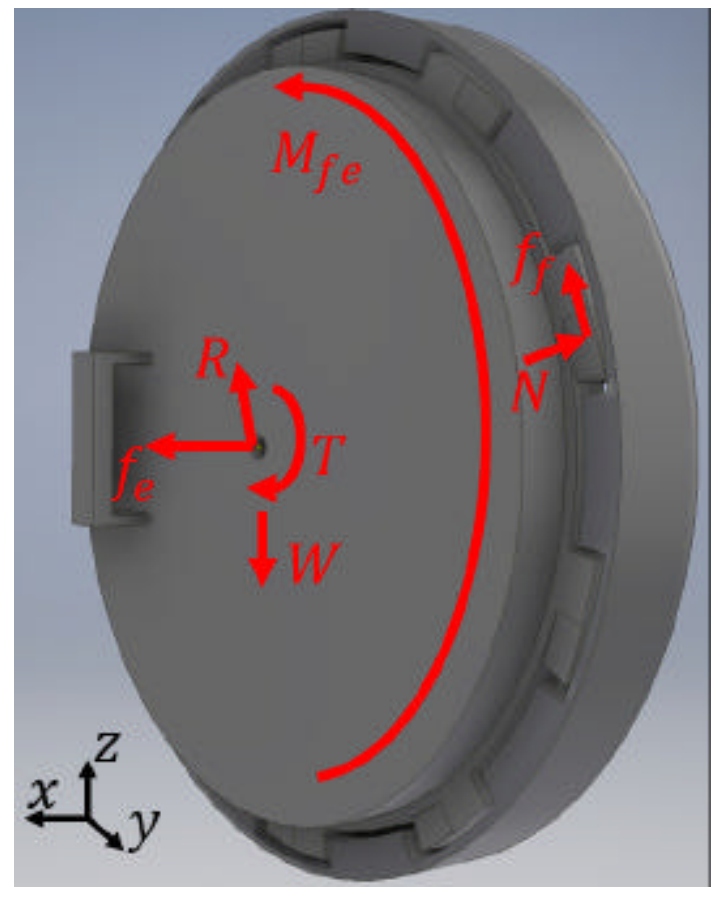

Fig. 7: Free body diagram of the door

implement a finite element analysis. Evans et al. (2012), the importance of implementing FEA can be observed.

Before starting to assume the measures of the mechanism, it must be known the nature of the forces and especially, understand how they can affect the closing operation, since, ignoring a variable can be so critical that the mechanism can not only malfunction but suddenly fail. In order to understand the system, the forces that are generated are explained and calculated throughout this study, allowing to proceed to the design of the pieces which must support the applied efforts and allow an average person to perform the action of adjusting the door without the need to make a great effort. The forces at the door, represented as vectors are illustrated in Fig. 7.

Figure 7 shows 5 forces and 2 moment. The force $\mathrm{f}_{e}$ is caused by the compression of the gasket, the pressure that is produced on it allows to create a hermetic seal. The force $\mathrm{N}$ is generated by the contact between each fixing tooth which produces the dry friction $\mathrm{f}_{\mathrm{f}}$ in a situation of imminent movement. These two forces are produced in each of the fixing teeth. The Moment $\mathrm{M}_{\mathrm{fe}}$ is the reaction, due to friction when it comes to making an angular movement in the door with respect to the gasket. This reaction is known as disc friction (Beer et al., 2013). The vector $\mathrm{T}$ represents the moment that must be applied to the door to achieve a movement. Finally, the forces $\mathrm{W}$ and $\mathrm{R}$ represent the weight of the door and the reaction of the axis that supports it.

Once the forces that must be modeled are known, the next step is to perform a static analysis to determine with what magnitude of $\mathrm{T}$ an imminent movement is generated. For example by Benavides et al. (2018) the static analysis allows to find an equation with which is the magnitude of a torque that leads a system to a situation of imminent movement. In this case, the same thing is done, the objective is to determine the torque on the door and thus, argue some things. As for example, the mechanical gain with which an actuator can produce the calculated torque.

In order to be able to carry out the analysis of the mechanism, it is fundamental to understand the degrees of freedom that it possesses. For example by Shariatee et al. (2014) before determining the homogenous transformation matrices it was necessary to understand the DOF (Degrees of Freedom) that were present. In this situation, the DOF allows to understand how the analyses that let to calculate the forces that the system should perform must be performed.

Like the systems of Fig. 1, the door by means of the fixing teeth moves linearly when rotating which causes a gasket to be compressed. This displacement is linear, however as Fig. 5 and 6, the hinge does not allow this movement. This means that, as the rotation is performed on the door, the fixing tooth will generate a rotational movement in the hinge. The analysis presented below is created assuming that the door moves linearly when rotating on its axis. When the calculations are finished, it is explained why it is valid to use equations found if, the mechanism does not have this degree of freedom. The free body diagram in the gasket (Fig. 8).

The gasket of Fig. 8 is responsible for completely sealing the imperfections of the machining of the door, this prevents the gases from being expelled and ensures that the operator never comes into contact with them. This element acts like a spring and exerts an axial force that depends on its compression. At the same time, it exerts a frictional force that prevents the relative displacement of the gasket with respect to the door.

The force $f_{e}$ is caused by the compression of the gasket, so, it must be related to the variation of the measure $h$ and the radii $r_{f e}$ and $r_{i e}$. The force $W_{e}$ represents the Weight of the gasket and is not taken into account in the analyses, since, its effect on the deformation of the gasket is ignored. The force $\mathrm{R}_{2}$ is caused by the compartment in which the gasket is located, this reaction prevents the gasket from moving. The Moment $M_{f e}$ is 


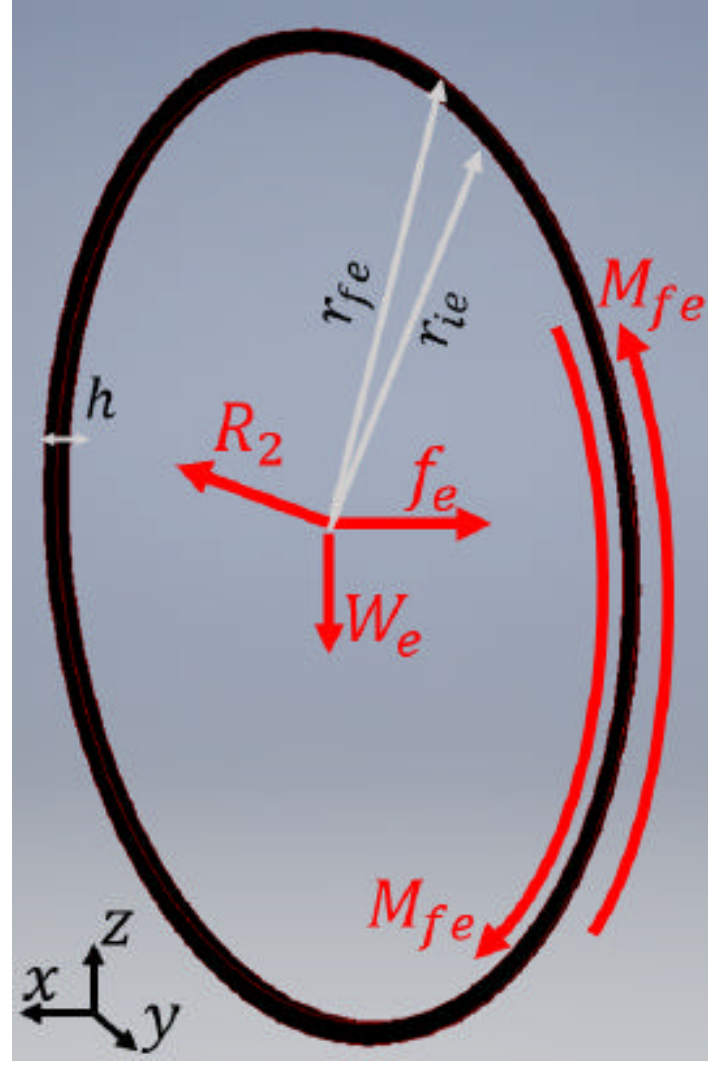

Fig. 8: Free body diagram of the gasket

caused by friction when trying to generate a relative displacement of the door with respect to the gasket. Because the gasket is not rotating, it is known that this moment must be counteracted by the piece that holds the gasket, for this reason the $\mathrm{M}_{\mathrm{fe}}$ Moment is repeated in the opposite direction. To determine the force $\mathrm{f}_{e}$, the equation that relates the unit strain and Hooke's law (Beer et al., 2014) must be combined. From these two equation, Eq. 1 is obtained:

$$
\mathrm{d} \delta=\frac{\mathrm{f}_{\mathrm{e}}}{\mathrm{AE}} \cdot \mathrm{dx}
$$

Solving Eq. 1 allows to see the relation that exists between the deformation $\delta$, the force exerted by the gasket $\mathrm{f}_{e}$, the area $\mathrm{A}$ of the gasket along the $\mathrm{x}$ axis, the Young's modulus $\mathrm{E}$ and the gasket height $\mathrm{h}$. For this situation, it is expected that the strain is uniform on the material, that the area is constant because it has a cylindrical shape and that the material is homogeneous, so, the solution of Eq. 1 results in Eq. 2:

$$
\delta=\frac{f_{e}}{A E} \cdot h
$$

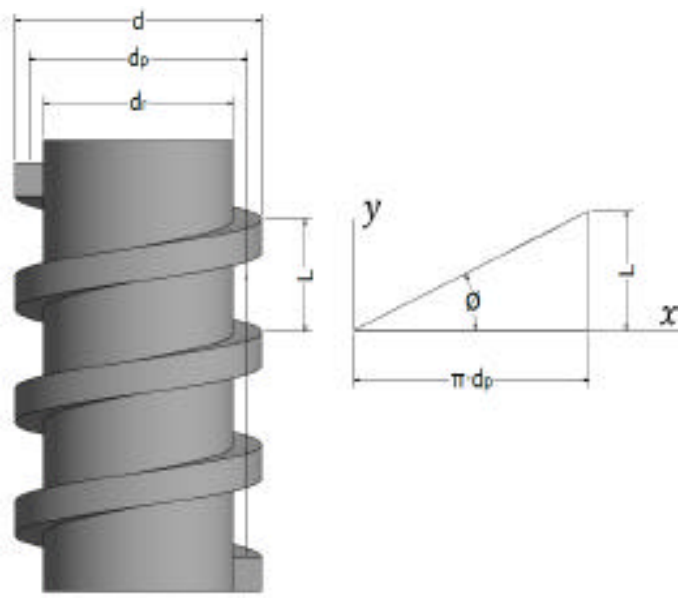

Fig. 9: Power screw

The gasket area is calculated in Eq. 3. This is the subtraction of the area from two circles delimited by radii $\mathrm{rf}_{\mathrm{e}}$ and $\mathrm{ri}_{\mathrm{e}}$ :

$$
A=\int_{0}^{2 \pi} \int_{r_{\mathrm{e}}}^{r_{\mathrm{re}}} \mathrm{rd} \theta d r=\left(\mathrm{rf}_{\mathrm{e}}^{2}-\mathrm{ri}_{\mathrm{e}}^{2}\right) \cdot \pi
$$

If the area calculated in Eq. 1 is replaced and the force of the gasket is cleared, Eq. 4 is obtained:

$$
f_{e}=\frac{A E}{h} \cdot \delta=\frac{\left(\mathrm{rf}_{e}^{2}-\mathrm{ri}_{e}^{2}\right) \cdot \pi E}{h} \cdot \delta
$$

The above equation allows us to find the axial force exerted by the gasket when it is deformed, a value that depends on the displacement of the door when turning. Previously, it was mentioned that the displacement of the door is linear, therefore, it can be said that the door works like a power screw where the fixing teeth are actually square ropes that allow combining a rotational displacement with a linear one. In Fig. 9, the relevant measurements of a power screw can be observed.

The Lead $\mathrm{L}$ represents the distance traveled by the nut in a rotation of $360^{\circ}$ on the screw, $\phi$ is the helix angle of the lead, $d$ is the largest diameter, $d_{s}$ is the smallest diameter and $\mathrm{d}_{\mathrm{p}}$ is the pitch diameter. To be able to relate the measurements of Fig. 9 with the door system, Fig. 10.

Figure 10 shows the measures that must be taken into account to relate the door with the power screw. Where $r_{p}$ is the pitch radius, $\mathrm{rf}_{\mathrm{p}}$ is the external radius and $\mathrm{ri}_{\mathrm{p}}$ is the internal radius. These radii are half the diameters shown in Fig. 9. 


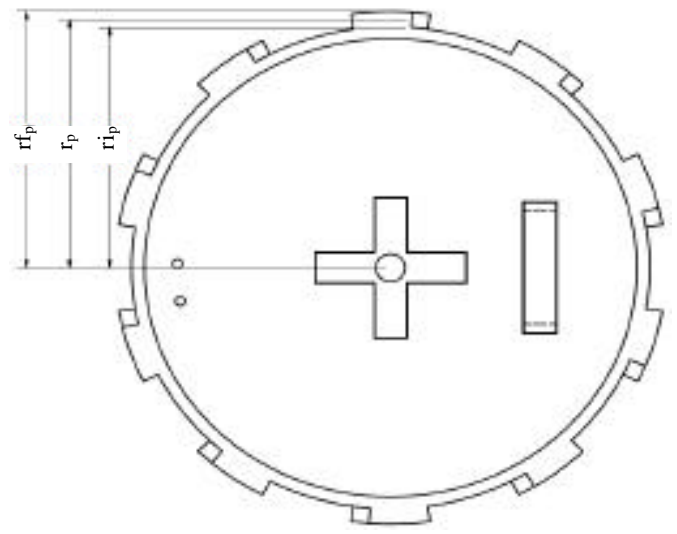

Fig. 10: Equivalent measurements on the door

By means of the lead $\mathrm{L}$, it is possible to calculate how much the gasket has been compressed according to what has rotated the door. From the triangle of Fig. 9, it can be found the equation of a line that represents the linear displacement of the door and therefore, the deformation of the gasket (Eq. 5):

$$
\delta=\frac{L}{2 \pi \cdot r_{p}} \cdot\left(\beta \cdot r_{p}\right)=\tan (\phi) \cdot \beta \cdot r_{p}
$$

The rotation of the door is $\beta$. If, Eq. 5 is replaced in Eq. 4, the axial force of the gasket is obtained in terms of rotation (Eq. 6):

$$
\mathrm{f}_{\mathrm{e}}=\frac{\left(\mathrm{rf}_{\mathrm{e}}^{2}-\mathrm{ri}_{\mathrm{e}}^{2}\right) \cdot \pi \mathrm{E}}{\mathrm{h}} \cdot \tan (\phi) \cdot \mathrm{r}_{\mathrm{p}} \cdot \beta
$$

Now it is necessary to know how the friction force behaves between the gasket and the door, since, it reacts in such a way that it tries to prevent the door from rotating (Fig. 11).

Figure 11 shows a friction force $\mathrm{df}_{\mathrm{fe}}$ which must generate a differential moment $\mathrm{dM}_{\mathrm{fe}}$. Since, the lever arm and the friction force in any position are located in the same plane, it can be said that the moment produced by each differential friction force already has a definite direction and therefore, the equivalent moment can be found by adding the magnitudes of each differential moment (Eq. 7):

$$
\mathrm{M}_{\mathrm{fe}}=\int \mathrm{r} \cdot \mathrm{df}_{\mathrm{fe}}=\int \mathrm{r} \cdot \mu_{\mathrm{se}} \cdot \mathrm{dN}_{\mathrm{e}}
$$

In Eq. 7, the friction force has been replaced by its relation to the force normal to the area in which it acts. The force $\mathrm{dN}_{\mathrm{e}}$ is the normal force acting in the differential

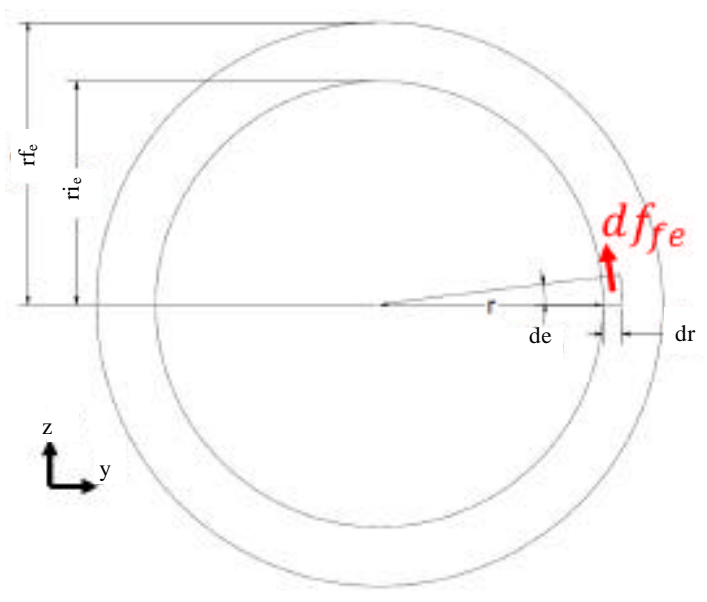

Fig. 11: Friction force on the gasket surface

area in which the friction force is evaluated. The coefficient of static friction $\mu_{\mathrm{se}}$ is the one that relates the friction between the gasket and the material of the door.

The normal force experienced by the entire gasket area is the axial force $\mathrm{f}_{\mathrm{e}}$. If this force is axial, it must be distributed uniformly over each differential area of the gasket, this means that the pressure on the gasket is uniform at all points and therefore, the differential force $\mathrm{dN}_{\mathrm{e}}$ can be replaced as shown in Eq. 8:

$$
\mathrm{M}_{\mathrm{fe}}=\int \mathrm{r} \cdot \mu_{\mathrm{se}} \cdot \frac{\mathrm{f}_{e}}{\left(\mathrm{rf}_{e}^{2}-\mathrm{ri}_{e}^{2}\right) \cdot \pi} \cdot \mathrm{dA}
$$

If the axial force found in Eq. 6 is replaced in Eq. 8 and the constants of the integral are separated, Eq. 9 and 10 are obtained:

$$
\begin{gathered}
\mathrm{M}_{\mathrm{fe}}=\frac{\mu_{\mathrm{se}} \cdot \mathrm{E} \cdot \tan (\phi) \cdot \mathrm{r}_{\mathrm{p}} \cdot \beta}{\mathrm{h}} \cdot \int \mathrm{r} \cdot \mathrm{dA} \\
\mathrm{M}_{\mathrm{fe}}=\frac{2}{3} \cdot \frac{\pi \cdot \mu_{\mathrm{se}} \cdot \mathrm{E} \cdot \tan (\phi) \cdot \mathrm{r}_{\mathrm{p}} \cdot\left(\mathrm{rf}_{\mathrm{e}}^{3}-\mathrm{ri}_{\mathrm{e}}^{3}\right)}{\mathrm{h}} \cdot \beta
\end{gathered}
$$

Equation 10 represents the maximum moment that the frictional force in the gasket can generate when the door is in an angular position $\beta$. It is important to keep in mind that this rotation only makes sense in Eq. 10 if the gasket is being compressed, otherwise there will be no axial force and therefore, there would be no friction.

To summarize the deduction about the gasket, Eq. 11 and 12 are presented with which the force $f_{e}$ and the moment $\mathrm{M}_{\mathrm{fe}}$ can be determined: 
(a)
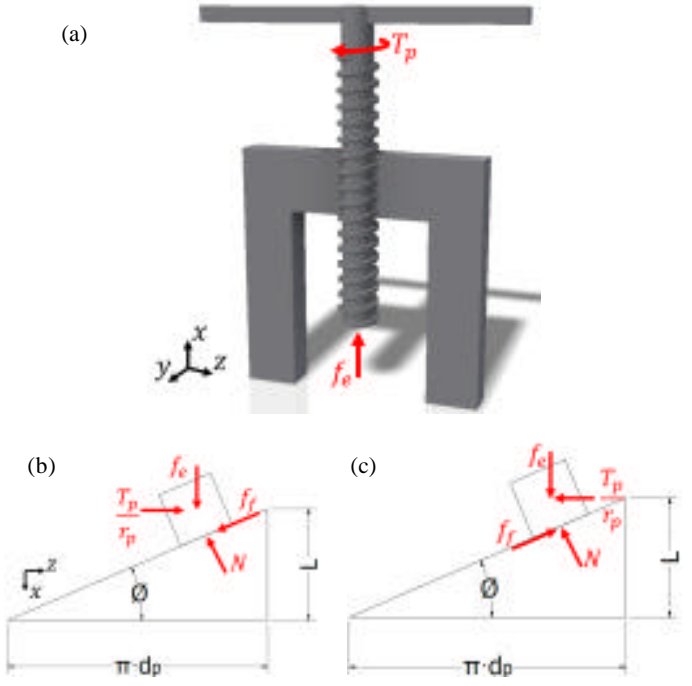

Fig. 12: Power screw: a) Power screw to be analysed and $b$, c) Simplified representation of the power screw

$$
\begin{gathered}
\mathrm{f}_{\mathrm{e}}=\frac{\left(\mathrm{rf}_{\mathrm{e}}^{2}-\mathrm{ri}_{e}^{2}\right) \cdot \pi \mathrm{E}}{\mathrm{h}} \cdot \tan (\phi) \cdot \mathrm{r}_{\mathrm{p}} \cdot \beta \\
\mathrm{M}_{\mathrm{fe}}=\frac{2}{3} \cdot \frac{\pi \cdot \mu_{\mathrm{se}} \cdot \mathrm{E} \cdot \tan (\phi) \cdot \mathrm{r}_{\mathrm{p}} \cdot\left(\mathrm{rf}_{\mathrm{e}}^{3}-\mathrm{ri}_{\mathrm{e}}^{3}\right)}{\mathrm{h}} \cdot \beta
\end{gathered}
$$

Now, it must be calculated the forces on the fixing teeth. In order to analyze this part of the system, Fig. 12 is presented. The power screw shown in Fig. 12a represents the door that is compressing the gasket. The torque $T_{p}$ has been applied that represents the torque to overcome the friction of the fixing teeth and the force of the gasket $\mathrm{f}_{\mathrm{e}}$. To find the minimum value with which an imminent movement is generated, a free-body diagram must be made as shown in Fig. 12b.

The analysis begins by finding the cube's static around the " $\mathrm{x}$ " and " $\mathrm{z}$ " axes. In order to understand how much torque must be applied to the door to adjust it, reference should be made to Fig. $12 \mathrm{~b}$ where the cube is to move up (opposite to the $\mathrm{x}$ axis) and clear the variable $\mathrm{T}_{\mathrm{p}}$. The sum on the $\mathrm{x}$ axis allows obtaining Eq. 13 from which $\mathrm{N}$ is cleared (Eq. 14):

$$
\begin{gathered}
\sum \mathrm{F}_{\mathrm{x}}=0=\mathrm{f}_{\mathrm{e}}-\mathrm{N}\left(\cos (\phi)-\mu_{\mathrm{sp}} \operatorname{sen}(\phi)\right) \\
\mathrm{N}=\frac{\mathrm{f}_{\mathrm{e}}}{\cos (\phi)-\mu_{\mathrm{sp}} \operatorname{sen}(\phi)}= \\
\frac{\left(\mathrm{rf}_{\mathrm{e}}^{2}-\mathrm{ri}_{\mathrm{e}}^{2}\right) \cdot \pi \mathrm{E}}{\left(\cos (\phi)-\mu_{\mathrm{sp}} \operatorname{sen}(\phi)\right) \mathrm{h}} \cdot \tan (\phi) \cdot \mathrm{r}_{\mathrm{p}} \cdot \beta
\end{gathered}
$$

The coefficient of friction $\mu_{s p}$ relates the friction between the strings which in this case are the fixing teeth of the door. If a sum of forces is made through the $\mathrm{z}$ axis, Eq. 15 is obtained:

$$
\sum \mathrm{F}_{z}=0=\frac{\mathrm{T}_{\mathrm{p}}}{\mathrm{r}_{\mathrm{p}}}-\mathrm{N}\left(\operatorname{sen}(\phi)+\mu_{\mathrm{sp}} \cos (\phi)\right)
$$

If, the torque $\mathrm{T}_{\mathrm{p}}$ is cleared from Eq. 15 and the normal force of Eq. 14 is replaced, Eq. 16 is obtained:

$$
\sum \mathrm{F}_{z}=0=\frac{\mathrm{T}_{\mathrm{p}}}{\mathrm{r}_{\mathrm{p}}}-\mathrm{N}\left(\operatorname{sen}(\phi)+\mu_{\mathrm{sp}} \cos (\phi)\right)
$$

This equation represents the minimum torque that must be performed to overcome only the friction of the fixing teeth. In order to obtain this relation in terms of the rotation of the door, Eq. 11 in 16 is replaced (Eq. 17):

$$
\begin{gathered}
\mathrm{T}_{\mathrm{p}}=\frac{\left(\operatorname{sen}(\phi)+\mu_{\mathrm{sp}} \cos (\phi)\right)\left(\mathrm{rf}_{\mathrm{e}}^{2}-\mathrm{ri}_{\mathrm{e}}{ }^{2}\right)}{\left(\cos (\phi)-\mu_{\mathrm{sp}} \operatorname{sen}(\phi)\right) \cdot \mathrm{h}} \\
\cdot \mathrm{r}_{\mathrm{p}}^{2} \cdot \pi \cdot \mathrm{E} \cdot \tan (\phi) \cdot \beta
\end{gathered}
$$

This equation that is also in terms of the angle of rotation of the door, must be taken into account with the moment found in Eq. 12. The sum of these moment is equivalent to the minimum torque that must be exerted on the axis of the door to generate an imminent movement in each angular position. If Eq. 17 and 12 are added, torque $\mathrm{T}_{1}$ is obtained (Eq. 18), required to perform the rotation in the door while the gasket is compressed:

$$
\mathrm{T}_{1}=\left(\begin{array}{c}
\frac{2 \mu_{\mathrm{se}}\left(\mathrm{rf}_{\mathrm{e}}{ }^{3}-\mathrm{ri}_{\mathrm{e}}{ }^{3}\right)}{3}+ \\
\frac{\left(\operatorname{sen}(\phi)+\mu_{\mathrm{sp}} \cos (\phi)\right)\left(\mathrm{rf}_{\mathrm{e}}{ }^{2}-\mathrm{ri}_{\mathrm{e}}{ }^{2}\right) \cdot \mathrm{r}_{\mathrm{p}}}{\left(\cos (\phi)-\mu_{\mathrm{sp}} \operatorname{sen}(\phi)\right)} \\
\frac{\mathrm{r}_{\mathrm{p}} \cdot \pi \cdot \mathrm{E} \cdot \tan (\phi)}{\mathrm{h}} \cdot \beta
\end{array}\right)
$$

If the same procedure is carried out analyzing Fig. 12b, for an imminent downward movement in the cube, the torque is calculated to undo the door (Eq. 19):

$$
\mathrm{T}_{2}=\left(\begin{array}{c}
\frac{2 \mu_{\mathrm{se}}\left(\mathrm{rf}_{\mathrm{e}}{ }^{3}-\mathrm{ri}_{\mathrm{e}}{ }^{3}\right)}{3}+ \\
\frac{\left(\mu_{\mathrm{sp}} \cos (\phi)-\operatorname{sen}(\phi)\right)\left(\mathrm{rf}_{\mathrm{e}}{ }^{2}-\mathrm{ri}_{\mathrm{e}}{ }^{2}\right) \cdot \mathrm{r}_{\mathrm{p}}}{\left(\cos (\phi)+\mu_{\mathrm{sp}} \operatorname{sen}(\phi)\right)}
\end{array}\right)
$$




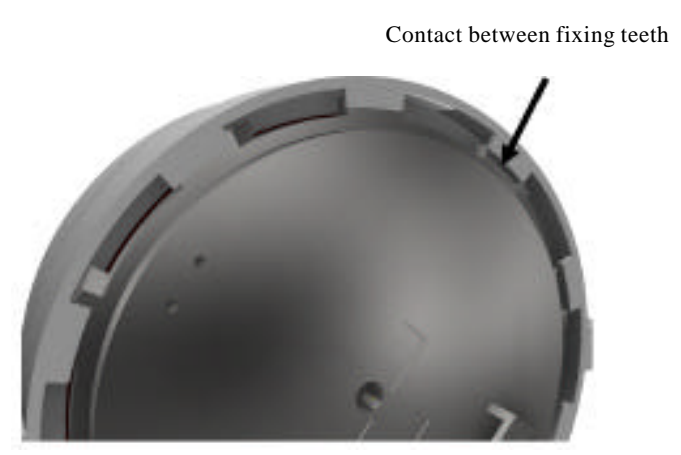

Fig. 13: Contact of the fixing teeth after a rotation $\beta_{-} f$ on the door

Where:

$\mathrm{T}_{1}=$ The Torque to adjust the door clockwise

$\mathrm{T}_{2}=$ The Torque to adjust the door counterclockwise

After having made an angular movement $\beta_{\mathfrak{f}}$ the fixing teeth come into contact as illustrated in Fig. 13. At this moment, the force and the moment that the gasket exerts can be calculated with Eq. 11 and 12, taking into account that the angle is $\beta_{\mathrm{f}}$ instead of $\beta$. In this way, Eq. 20 and 21 are obtained:

$$
\begin{gathered}
\mathrm{f}_{\mathrm{e}}=\frac{\left(\mathrm{rf}_{\mathrm{e}}^{2}-\mathrm{ri}_{\mathrm{e}}^{2}\right) \cdot \pi \mathrm{E}}{\mathrm{h}} \cdot \tan (\phi) \cdot \mathrm{r}_{\mathrm{p}} \cdot \beta_{\mathrm{f}} \\
\mathrm{M}_{\mathrm{fe}}=\frac{2}{3} \cdot \frac{\pi \cdot \mu_{\mathrm{se}} \cdot \mathrm{E} \cdot \tan (\phi) \cdot \mathrm{r}_{\mathrm{p}} \cdot\left(\mathrm{rf}_{\mathrm{e}}^{3}-\mathrm{ri}_{\mathrm{e}}^{3}\right)}{\mathrm{h}} \cdot \beta_{\mathrm{f}}
\end{gathered}
$$

Having reached the angular position $\beta_{\mathrm{f}}$, the fixing teeth no longer compress the gasket. So, it can be said that both the axial force and the frictional moment, caused by the gasket, reach a constant value and the rotation stops affecting the magnitude of these values. Although, the inclination of the fixing teeth is now zero, friction is still experienced in these. The effect of this friction is calculated in a manner very similar to the procedure performed for gasket with respect to the friction moment. Following the same procedure of Eq. 7, taking into account that the fixing teeth are analyzed, Eq. 22 is obtained:

$$
\mathrm{T}_{\mathrm{p}}=\int \mathrm{r} \cdot \mu_{\mathrm{sp}} \cdot\left(\frac{\mathrm{f}_{\mathrm{e}}}{\mathrm{A}}\right) \cdot \mathrm{dA}=\mu_{\mathrm{sp}} \cdot\left(\frac{\mathrm{f}_{\mathrm{e}}}{\mathrm{A}}\right) \cdot \int \mathrm{r} \cdot \mathrm{dA}
$$

The axial force generated by the gasket must be counteracted by the normal force of the surface of the fixing tooth, for this reason the force $f_{e}$ is still present. On the other hand, the area implemented is one that experiences friction and in the integral is a constant, so, it can be rearranged as shown in Eq. 22. The area that experiences friction is determined by the radii $\mathrm{fi}_{\mathrm{p}}$ and $\mathrm{rf}_{\mathrm{p}}$ and the amount of fixing teeth present $\mathrm{n}$. By replacing the total area and the differential area of the integral, Eq. 23 is obtained which represents the friction of discs between the fixing teeth:

$$
\mathrm{T}_{\mathrm{p}}=\frac{2 \mu_{\mathrm{sp}}\left(\mathrm{rf}_{\mathrm{p}}^{3}-\mathrm{ri}_{\mathrm{p}}^{3}\right)}{3\left(\mathrm{rf}_{\mathrm{p}}^{2}-\mathrm{ri}_{\mathrm{p}}^{2}\right)} \cdot \mathrm{f}_{\mathrm{e}}
$$

If the force of the gasket is replaced (Eq. 20), Eq. 24 is obtained:

$$
\mathrm{T}_{\mathrm{p}}=\frac{2 \mu_{\mathrm{sp}}\left(\mathrm{rf}_{\mathrm{p}}^{3}-\mathrm{ri}_{\mathrm{p}}^{3}\right)}{3\left(\mathrm{rf}_{\mathrm{p}}^{2}-\mathrm{ri}_{\mathrm{p}}{ }^{2}\right)} \cdot \frac{\left(\mathrm{rf}_{\mathrm{e}}^{2}-\mathrm{ri}_{\mathrm{e}}^{2}\right) \cdot \pi \mathrm{E}}{\mathrm{h}} \cdot \tan (\phi) \cdot \mathrm{r}_{\mathrm{p}} \cdot \beta_{\mathrm{f}}
$$

Once again, an equation that represents the minimum torque that must be done to overcome the friction force in the fixing teeth is obtained. Since, friction in the gasket is also present, it must be taken into account by adding Eq. 24 and 21. The total torque that must be made to rotate the door when reaching the angle $\beta_{\mathrm{f}}$ is calculated with Eq. 25:

$$
\mathrm{T}_{3}=\frac{2 \pi \mathrm{E} \tan (\phi) \mathrm{r}_{\mathrm{p}} \cdot}{3 \mathrm{~h}} \cdot\left(\begin{array}{l}
\mu_{\mathrm{se}}\left(\mathrm{rf}_{\mathrm{e}}^{3}-\mathrm{ri}_{\mathrm{e}}^{3}\right) \\
+\mu_{\mathrm{sp}} \frac{\left(\mathrm{rf}_{\mathrm{p}}^{3}-\dot{\mathrm{r}}_{\mathrm{p}}^{3}\right)\left(\mathrm{rf}_{\mathrm{e}}^{2}-\mathrm{ri}_{\mathrm{e}}^{2}\right)}{\left(\mathrm{rf}_{\mathrm{p}}{ }^{2}-\dot{\mathrm{r}}_{\mathrm{p}}{ }^{2}\right)}
\end{array}\right) \cdot \beta_{\mathrm{f}}
$$

The variable $T_{3}$ represents the touch that must be made in either direction to move the door. In this case, there is no inclination in the surface that hinders or helps to generate the movement. In addition to this, it can be seen that Eq. 25 is a constant, this value does not change with the rotation of the door and must be applied, if the angular position is $\beta>\beta_{\mathrm{f}}$. For positions less than or equal to $\beta_{\mathrm{f}}$ Eq. 18 and 19 must be implemented, depending on the direction of rotation.

In summary, in this section of the study the static of the door has been analyzed in order to find the minimum torque with which an imminent movement can be generated on it. Equation 18 and 19 should be applied when the contact of the fixing teeth generates a linear movement on the door where Eq. 18 represents the torque to turn the door while the gasket is compressed. If the door is in an angular position where the gasket is not compressed, Eq. 25 must be implemented regardless of the direction of rotation. The meaning of each variable is shown in Table 1. 
Table 1: Variables implemented

\begin{tabular}{|c|c|}
\hline Variables & Meanings \\
\hline$f_{e}$ & $\begin{array}{l}\text { Axial force exerted by the gasket when compressed. It must be } \\
\text { calculated in the program }\end{array}$ \\
\hline $\mathrm{M}_{\mathrm{fe}}$ & $\begin{array}{l}\text { Maximum Moment of friction caused by the gasket. It must be } \\
\text { calculated in the program }\end{array}$ \\
\hline $\mathrm{N}$ & $\begin{array}{l}\text { Normal force on the fixing teeth. It must be calculated in the } \\
\text { program }\end{array}$ \\
\hline$f_{f}$ & $\begin{array}{l}\text { Friction force on the fixing teeth. It must be calculated in the } \\
\text { program }\end{array}$ \\
\hline $\mathrm{T}$ & Torque applied on the door. It is calculated \\
\hline $\mathrm{T}_{1}$ & Torque to turn the door clockwise $\beta \leq \beta_{\mathrm{f}}$. It is calculated \\
\hline $\mathrm{T}_{2}$ & Torque to turn the door counterclockwise $\beta \leq \beta_{\mathrm{f}}$. It is calculated \\
\hline $\mathrm{T}_{3}$ & Minimum Torque to turn the door $\beta>\beta_{\mathrm{f}}$. It is calculated \\
\hline $\mathrm{T}_{\mathrm{p}}$ & $\begin{array}{l}\text { Minimum torque to overcome friction in the fixing teeth. It is } \\
\text { calculated }\end{array}$ \\
\hline$\mu_{\mathrm{se}}$ & $\begin{array}{l}\text { Coefficient of static friction between the gasket and the door. } \\
\text { Data that the user enters }\end{array}$ \\
\hline$\mu_{\mathrm{sp}}$ & $\begin{array}{l}\text { Coefficient of static friction between the strings. Data that the } \\
\text { user enters }\end{array}$ \\
\hline$\phi$ & Helix angle or lead of the fixing tooth. It is calculated \\
\hline $\mathrm{E}$ & Young's module of gasket. Data that the user enters \\
\hline$\beta$ & $\begin{array}{l}\text { Angle that has rotated the door, since, it comes into contact with } \\
\text { the gasket. It is calculated }\end{array}$ \\
\hline$\beta_{\mathrm{f}}$ & $\begin{array}{l}\text { Angle for which the gasket is no longer compressed. It is } \\
\text { calculated }\end{array}$ \\
\hline$\delta$ & Deformation of the gasket. Data that the user enters \\
\hline$r_{p}$ & Step radius of the fixing tooth $\mathrm{rf}_{\mathrm{p}}+\mathrm{ri}_{\mathrm{p}} / 2$. It is calculated \\
\hline $\mathrm{ri}_{\mathrm{p}}$ & Internal radius of the fixing tooth. Data that the user enters \\
\hline $\mathrm{rf}_{\mathrm{p}}$ & External radius of the fixing tooth. Data that the user enters \\
\hline $\mathrm{rf}_{e}$ & External radius of the gasket. Data that the user enters \\
\hline $\mathrm{ri}_{\mathrm{e}}$ & Internal radius of the gasket. Data that the user enters \\
\hline $\mathrm{h}$ & Gasket height. Data that the user enters \\
\hline$\underline{\mathrm{L}}$ & Advancement of the fixing tooth. Data that the user enters \\
\hline
\end{tabular}

Next, the previously mentioned equations are used to apply them in an algorithm that performs the calculations and presents the most relevant data needed in the design process of these doors. The algorithm that is developed applies to any system that can be represented as a power screw, square-wound, that is compressing a gasket of cylindrical shape.

If the mechanism does not have a linear movement but by means of a hinge, rotates around an axis as in Fig. 6, the following should be considered.

Figure 14 shows how the gasket begins to be compressed. As the door approaches the gasket their surfaces slowly begin to come into contact. This compression must generate a force $f_{e}$ that is not axial because the deformation is not uniform along the gasket. Since, the compressed material is smaller than it would be in a linear movement, it can be expected that the force $f_{e}$ begins to be smaller. In addition as the force is not axial, it starts located near the axis of rotation of the hinge while the force of the fixing teeth is further away. This difference in distances generates a mechanical gain that facilitates the compression of the gasket. As the rotation locates the gasket parallel to the door, the forces will approach the calculated ones. Regarding the maximum Torque calculated for $\mathrm{T}$, it can be expected that, thanks to the mechanical gain, the movement on the door will be generated.

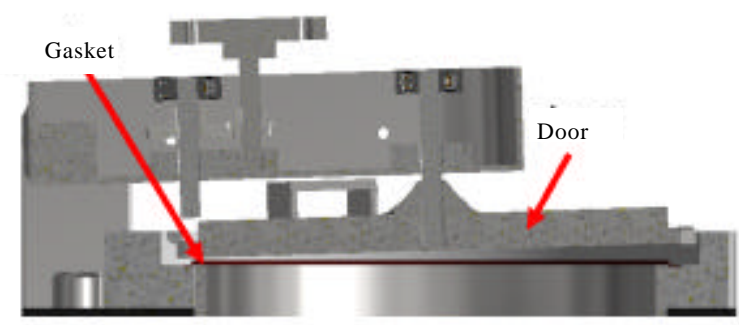

Fig. 14: Compression of the gasket in the rotational movement

\section{RESULTS AND DISCUSSION}

Structured programming: Now a days, the use of computer systems allows calculations and processes in a matter of seconds. The ease with which tasks are executed, mechanisms are designed and processes are automated depend greatly on the algorithms. In order to improve the design process of hermetic sealing mechanisms such as the one presented in Section 1 of this study, an algorithm is developed and an interface is presented that allows all the relevant calculations required by a designer to be carried out.

Structured programming, control instructions and the top-down refinement method for pseudo-code algorithms are the tools implemented to fully explain the program. The pseudo-code is written in italics to remember that it is part of the algorithm that is being developed, in addition, the instructions are listed and the indentation (blank spaces) is modified to indicate the presence of blocks. To begin with the explanation, the top of the algorithm is shown which transmits the general function of the program: calculate and graph the variables present in the mechanical system.

Once having the top of the algorithm, it is proceeded to perform the first refinement, in which the program is divided into 3 phases. The initiation phase, the processing phase and the termination phase:

- Initialize the required variables

- Enter and adjust the program data

- Calculate and produce graphs to show the relevant information

To know which variables to initiate and how to initiate them, it is pertinent to review Table 1 again. Some of these variables must be entered by the user and others calculated in the execution of the program. All of these can contain numbers with a decimal point, so, it is convenient to declare double or float variables. Next, refinement is performed on the initialize the required variables section: all the variables in Table 1 must be declared double without assigning any value, except 
the variables $f_{e}, \beta, T, N, f_{e}$ and $f_{F}$ which should be a one-dimensional double array with no defined size. Declare a Boolean variable called "verification" and initialize it as "false". Declare the variables double $\rho$ and $\tau$. They should be assigned the values that the programmer considers acceptable and should not be equal to zero.

Only the verification variables, $\rho$ and $\tau$ have been initialized because they do not depend on the user. As the others must be specified, the handling of exceptions should be kept in mind to avoid errors in the execution of the program. For this reason, the verification variable is implemented to analyze user errors. The variables $\rho$ and $\tau$ determine the size of the arrangements. These are explained later.

In the processing phase, the user must enter the data for certain variables in Table 1. Then a verification is carried out, so that, the termination phase can be executed without errors. The refinement for the instruction enter and adjust the program data is: obtain the following variables from the user: $\mu_{\mathrm{se}}, \mu_{\mathrm{sp}}, \mathrm{E}, \delta$, $r i_{p}, r f_{p}, r i_{e}, r f_{e}, h, L$.

If all the data were entered and are numbers, a value equal to "true" should be assigned to "verification" and adjust the units of each variable according to the system of units implemented.

In order to perform the calculation of the other variables, phase 3 is refined, as follows: if "verification" is equal to false, continue to step 38 . The pitch radius is calculated $r_{p}=r r_{p}+r i_{p} / 2$. The helix angle, in radians is calculated $\phi=\tan ^{-1}\left(\mathrm{~L} / 2 \pi \cdot \mathrm{r}_{\mathrm{p}}\right) \cdot \beta_{\mathrm{f}}=\delta / \tan (\varnothing) \cdot \mathrm{r}_{\mathrm{p}}$ is calculated. The size of the arrays $\beta, T, N, f_{e}$ and $f_{f}$ are defined. They must have only one row and (floor $\left.\left(\beta_{\mathrm{f}}(1+\mathrm{p} / \tau)\right)+1\right)$ columns.

Assign the variable $\beta_{\mathrm{f}}$ values from 0 to (floor $\left.\left(\beta_{\mathrm{f}}(1+\mathrm{p} / \tau) \cdot \tau\right) \cdot 180 / \pi\right)$ in steps of $(\tau \cdot 180 / \pi)$. Using Eq. 18, find $\mathrm{T}_{1}$ from 0 to floor $\left(\beta_{\mathrm{f}} \tau\right) \tau$ radians in steps of $\tau$. Each value found from $T_{1}$ must be assigned to the cells of $T$ in ascending order. From column 1 to column $\left(\beta_{f} / \tau\right)+1$. Using Eq. 20, find $\mathrm{T}_{3}$ to assign this value to the cells of the $\mathrm{T}$ array from the column floor $\left(\beta_{\mathrm{f}} / \tau\right)+2$ to the column (floor $\left.\left(\beta_{\mathrm{f}}(1+\mathrm{p} / \tau)\right)+1\right)$. Create the first graph with the arrays $\mathrm{T}$ and $\beta_{\mathrm{f}}$ with a red trace. Check the cells of array $\mathrm{T}$ and find the highest value contained in them. Indicate to the user that this value is the maximum torque that must be made to the door throughout the movement. Using Eq. 19, find $\mathrm{T}_{2}$ from 0 to floor $\left(\beta_{\mathrm{f}} \tau\right) \tau$ radians in steps of $\tau$. Each value found must be assigned to the cells of $\mathrm{T}$ in ascending order. From column 1 to column floor $\left(\beta_{\mathrm{f}} / \tau\right)+\mathrm{T}$. Change the sign of each value that contains $\mathrm{T}$ to indicate that the torque is opposite. Overwrite the first graph with arrays $\mathrm{T}$ and $\beta_{\mathrm{f}}$ with a blue trace. Find Eq. 14 from 0 to floor $(\beta / \tau) \tau$ radians in steps of $\tau$. Each value found must be assigned to the cells of $\mathrm{N}$ in ascending order. From column 1 to column (floor $\left(\beta_{f} \tau\right)+1$. Find Eq. 20 to assign this value to the cells of the array $\mathrm{N}$ and $\mathrm{f}_{\mathrm{e}}$ from column floor $\left(\beta_{\mathrm{f}} / \tau\right)+2$ to column floor $\left.\left(\beta_{\mathrm{f}}(1+\mathrm{p} / \tau)\right)+1\right)$. Create the second graph with the arrays $N$ and $\beta_{f}$ with a red trace. Obtain the values of the cells $(1,1)$ up to $\left(1\right.$, floor $\left.\left(\beta_{\mathrm{f}} \tau\right)+1\right)$ of the array $\mathrm{N}$ and multiply them by $\mu_{\mathrm{sp}}$. Each value found must be assigned to the cells of $f_{\mathrm{f}}$ in ascending order, from column 1 to column (floor $\left(\beta_{\mathrm{f}} / \tau\right)+1$ ). Find $\mathrm{T}_{\mathrm{p}}$ using Eq. 24 and divide that value by $r_{p}$. The result of this operation must be assigned to the cells of the array $\mathrm{f}_{\mathrm{f}}$ from column floor $\left(\beta_{\mathrm{f}} / \tau\right)+2$ to column (floor $\left.\left(\beta_{\mathrm{f}}(1+\mathrm{p} / \tau)\right)+1\right)$. Create the third graph with the arrays $f_{\mathrm{f}}$ and $\beta_{\mathrm{f}}$ with a red trace. Find Eq. 26 from 0 to floor $\left(\beta_{f} \tau\right) \tau$ radians in steps of $t$. Each value found must be assigned to the cells of $\mathrm{N}$ in ascending order from column 1 to column floor $\left(\beta_{\mathrm{f}} / \tau\right)+1$ :

$$
\mathrm{N}=\frac{\left(\mathrm{rf}_{e}^{2}-\mathrm{ri}_{e}^{2}\right) \cdot \pi \mathrm{E}}{\left(\cos (\phi)+\mu_{\mathrm{sp}} \operatorname{sen}(\phi)\right) \mathrm{h}} \cdot \tan (\phi) \cdot \mathrm{r}_{\mathrm{p}} \cdot \beta
$$

Overwrite the second graph with the arrays $N$ and $\beta_{\mathrm{f}}$ with a blue trace. Obtain the values of the cells $(1,1)$ up to $\left(1\right.$, floor $\left.\left(\beta_{\mathrm{f}}(1+\mathrm{p} / \tau)\right)+1\right)$ of the array $\mathrm{N}$ and multiply them by $\mu_{s p}$. Each value found must be assigned to the cells of $\mathrm{f}_{\mathrm{f}}$ in ascending order, from column 1 to column floor $\left(\beta_{\mathrm{f}}(1+\mathrm{p} / \tau)\right)+1$. Change the sign of each value that contains the array $f_{\mathrm{f}}$ and overwrite the third graph with the arrays $\mathrm{f}_{\mathrm{f}}$ and $\beta_{\mathrm{f}}$ with a blue trace. Find Eq. 11 from 0 to floor $\left(\beta_{\mathrm{f}} \tau\right) \tau$ radians in steps of $\tau$. Each value found must be assigned to the cells of $f_{e}$ in ascending order, from column 1 to column floor $\left(\beta_{\mathrm{f}}(1+\mathrm{p} / \tau)\right)+1$. Create the fourth graph with the arrays $\mathrm{f}_{\mathrm{e}}$ and $\beta_{\mathrm{f}}$ with a red trace. Show $\phi$ to the user. If the array $\mathrm{T}$ has a cell with a value greater than zero, the user must be told that the system is not self-blocking. Otherwise, it must be indicated that it is. Using Eq. 20, indicate to the user the maximum axial force of the gasket. Using Eq. 21, indicate to the user the maximum disc friction caused by the gasket. By means of Eq. 14, evaluated in $\beta_{\mathrm{f}}$ indicate to the user the maximum normal force in the fixing teeth. The value calculated in the previous step must be multiplied by $\mu_{\mathrm{sp}}$ to indicate to the user the maximum frictional force of the gasket. Review the cells in array $\mathrm{T}$ and find the lowest value contained in them. Indicate to the user that this value is the minimum torque that must be made to the door throughout the movement. If "verification" is equal to false, show error message. End.

In instruction 6 , the verification variable has been implemented to control whether calculations should be performed or not. If verification is equal to false, this 


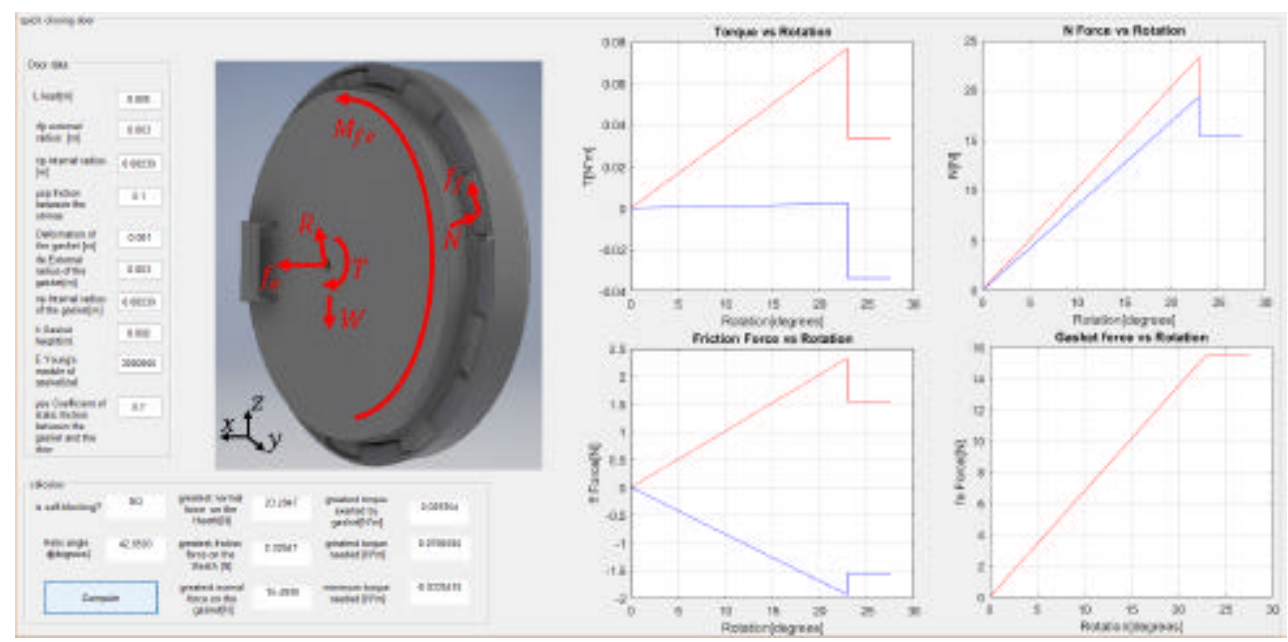

Fig. 15: Interface that contains the algorithm explained

means that the user did not enter all the data or any of them is not a number. Therefore, the program has already been protected against user errors.

The function floor(), implemented to define the size of the arrays is responsible for approximating the argument to the next smallest integer.

As it can be seen, the size of the arrays depends on two constants symbolized as $\rho$ and $\tau$. The $\tau$ determines the increment with which the program moves through the angular displacement of the door, this can be calculated as $\beta_{\mathrm{f}} 1000$. While $\rho$ specifies the percentage of $\beta_{\mathrm{f}}$ that is taken into account to plot the positions $\beta>\beta_{\mathrm{f}}$, this value cannot be equal to zero, since, errors would occur when evaluating some positions in the arrays. It is recommended that this represents $20 \%$, i.e., 0.2 . Figure 15 shows the effect of these variables. It has been decided to graph in two colors to emphasize that, depending on the direction of the turn, the forces are affected. In Fig. 15, the red line symbolizes the torque that must be done to adjust the door while the blue color is to undo it.

In instruction 17, the sign of the cells of the array $\mathrm{T}$ has been changed, in order to emphasize that the applied torque must be in the opposite direction. Equation 18-20 indicate the magnitude of the applied torque. When these were deduced, torque was assumed in a certain direction. If at the moment of calculating the torque the result is positive, this means that it has the assumed direction. When this is negative, it means that the direction is opposite to the one that was defined. Therefore, if at the time of calculating Eq. 18 and 19 positive signs are obtained, this does not mean that the torque has the same direction in both cases. For Eq. 18, a positive value indicates a clockwise torque while in Eq. 19 it indicates a direction opposite to clockwise direction. To avoid

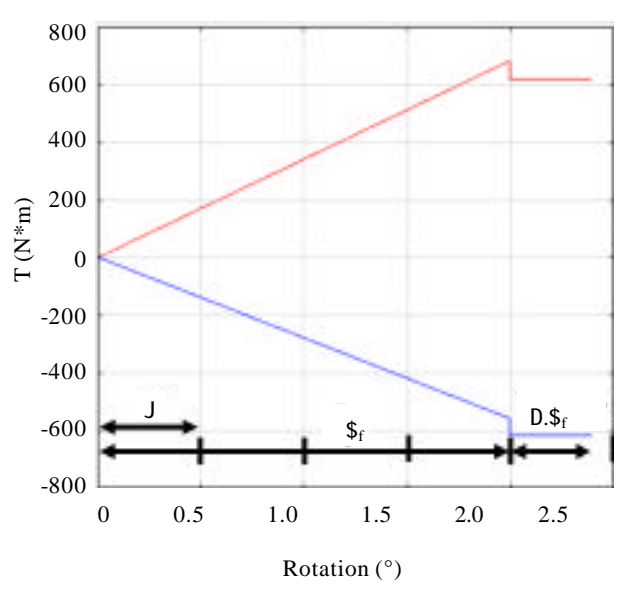

Fig. 16: Effect of the variables pand $\tau$

confusing the user, it is assumed that a negative sign, for the torque $\mathrm{T}$, indicates an opposite direction to the clockwise direction.

For the friction force something similar happens. A positive value indicates that the direction of the force is the one assumed when the door is being adjusted while a negative one is when it is undoing. For the case of $\mathrm{N}$ and $\mathrm{f}_{\mathrm{e}}$ forces, their directions are always normal to the surface, so, the direction will always be the same. For this reason there is no change of sign (Fig. 16).

In instruction 23 , the torque $T_{p}$ is calculated and then the result is divided by $r_{p}$. The reason why this is done is to find an equivalent force that performs this same moment around the axis from a distance $r_{p}$. The force that is found represents the friction for the positions $\beta>\beta_{\mathrm{f}}$. The above is a simplification similar to that made in the power screw to obtain Fig. 12. Since, the torque $\mathrm{T}_{\mathrm{p}}$ is a 
combination of several tangential forces around several circles, an approximation is made where there is only one force located in the pitch radius.

An example of an interface which contains the previous algorithm is shown in Fig. 16. In Fig. 16, the most important sections of the interface can be seen. In the panel on the left, the user enters the data of the door that he wants to analyze. In the lower panel, the relevant data of all the calculations are shown and finally, in the right section of the interface, the variables are plotted.

Thanks to this interface, it can be quickly calculated the forces acting on the door. This allows a finite element analysis to be done to know how the efforts are distributed over the material with which the safety factor of the mechanical system can be determined in a few steps. The objective of this algorithm is to eliminate most of the calculations, to decrease the design time.

Application: In order to test the interface, the analysis is carried out for a "quick closing door" with the values shown in Table 2. The door does not have a linear displacement, so, the interface will calculate an approximation of the results. However, as explained in Section 1, this is not a problem.

In Fig. 17 are shown the results of the algorithm with the data of Table 2. Initially the most important data is the maximum torque that is required, since with this one must argue the mechanical gain required for a motor, hydraulic cylinder or person to perform the movement of the mechanism.
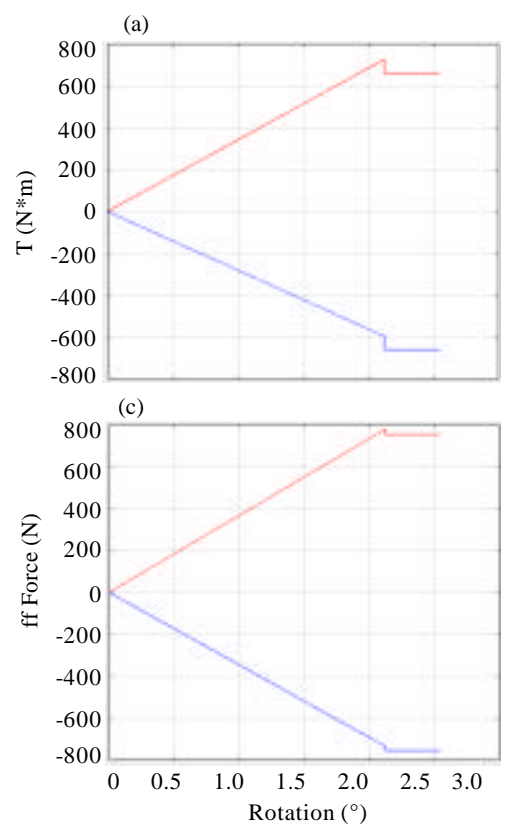

The maximum torque calculated is $724.3 \mathrm{~N}$. So, a composite gear train that generates a mechanical gain equal to 20 is implemented. Subsequently, the efforts in each piece of the system must be checked, so that, they can support the number of cycles expected of the machine. The scale system is shown in Fig. 18.

An example to analyze the efforts on the door is seen in Fig 19. The force of the gasket causes a deflection in the strings of the door and therefore, there are efforts that can cause the rupture of these. In this case, the dimensions of the material cause efforts to be sufficiently low, so that, most of the steels can be implemented.

In previous analysis only takes into account the strength of the gasket, however, must take into account the internal pressure that occurs when the heating process is performed. In summary, thanks to the interface, it is possible to know the forces that are generated when adjusting the mechanism. With these forces, it can be analyzed both the gain system and the efforts and safety factors that occur in the material.

\begin{tabular}{ll} 
Table 2: Characteristics of the door & \\
\hline Variables & Values \\
\hline$\mu_{\mathrm{se}}$ & 0.6 \\
$\mu_{\mathrm{sp}}$ & 0.35 \\
$\mathrm{E}$ & $2160727 \mathrm{~Pa}$ \\
$\delta$ & $1 \mathrm{~mm}$ \\
$\mathrm{ri}_{\mathrm{p}}$ & $32.3 \mathrm{~cm}$ \\
$\mathrm{rf}_{\mathrm{p}}$ & $34 \mathrm{~cm}$ \\
$\mathrm{rf}_{\mathrm{e}}$ & $31.7 \mathrm{~cm}$ \\
$\mathrm{ri}_{\mathrm{e}}$ & $31.6 \mathrm{~cm}$ \\
$\mathrm{~h}$ & $2 \mathrm{~mm}$ \\
$\mathrm{~L}$ & $5.4 \mathrm{~cm}$ \\
\hline
\end{tabular}
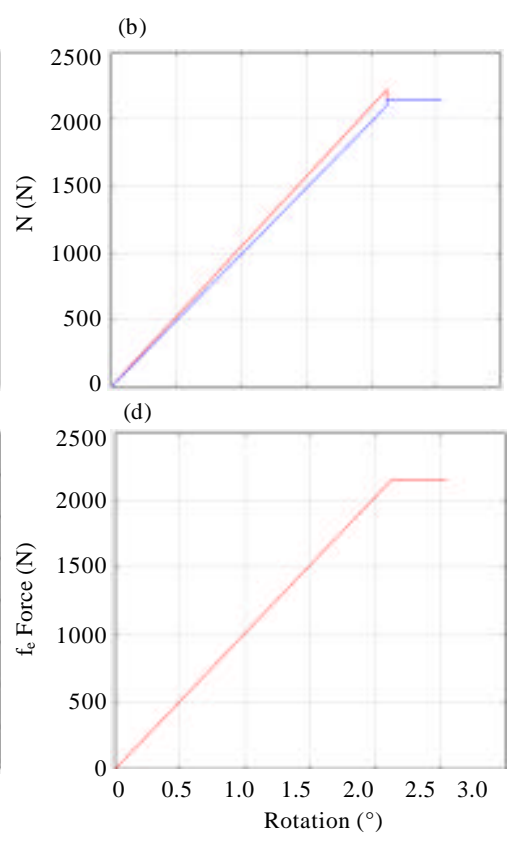

Fig. 17: Application with the interface. a) Torque vs. rotation; b) N force vs. rotation; c) Friction force vs. rotation and d) Gasket force vs. rotation 


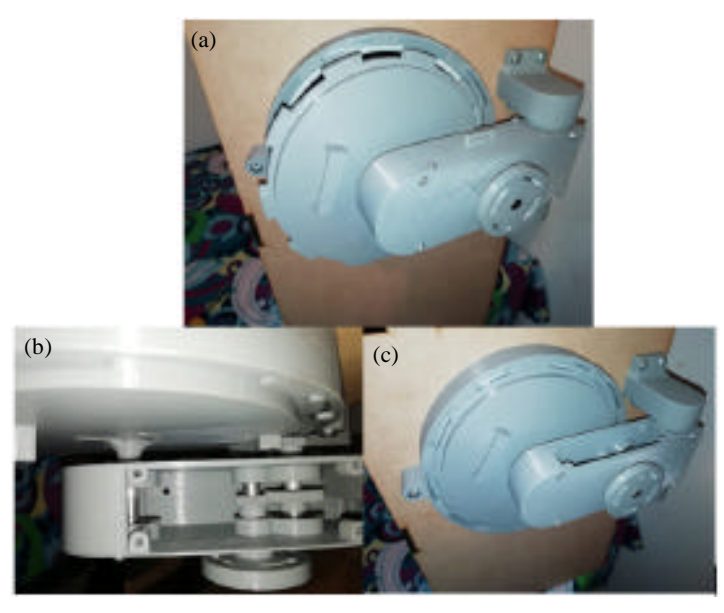

Fig. 18: a-c) Scaled model implemented

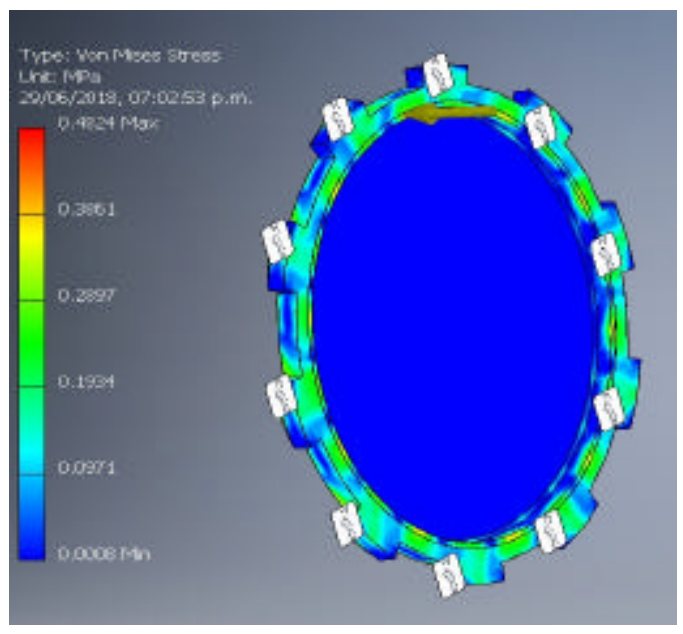

Fig. 19: Analysis by finite elements

\section{CONCLUSION}

Through the analysis performed, it is possible to calculate all the forces and moment that occur in the mechanism which allows an analysis of efforts to argue the safety factor of the system.

Because it is possible to determine the torque at any angular position of the door, the algorithm can calculate whether the system is self-blocking or not. This is very important, if it is not wanted a movement in the door, in the positions $\beta \leq \beta_{\mathrm{f}}$ when the applied torque is zero.

Through structured programming which implements the structures of sequence, selection and iteration, it is possible to order all the steps with which the interface of Fig. 16 works. With the pseudocode exposed, any sequential programming language can perform the calculations of forces and moment that affect the "quick closing door" system.
The entire process to calculate the forces and moment that are presented in the "quick closing door" system can be programmed, allowing it to reduce the time it takes to design this mechanism.

When the degree of freedom that allows the door to move linearly is eliminated with respect to the gasket, the deduced equations can still be implemented. The way in which the gasket is compressed in a solely rotational movement, generates a force that is easier to overcome compared to the system analyzed. This indicates that, if a linear movement is not assumed, the calculated maximum torque must work in the same way to generate the movement of the system.

\section{ACKNOWLEDGEMENT}

The research for this study was supported by Davinci research Group of Nueva Granada Military University and GITECX research Group of University of the Llanos. The researchers are grateful with the mentioned universities by support this research.

\section{REFERENCES}

Anonymous, 2018a. A brilliant invention. SCHOLZ Maschinenbau GmbH \& Co., Coesfeld, Germany. https://www.scholz-autoclaves.com/english/quickclosing-doors/

Anonymous, 2018b. Reactor \& special pressure vessel-QC series. Ilshin Autoclave Co., Ltd., Daejeon, South Korea.

Anonymous, 2018c. What is an impulse sealer?. Boatman Marking Inc., South El Monte, California. http://www.boatmanmarking.com/What_is_an_Imp ulse_Sealer-10000037.aspx

Beer, F.P., E.R. Johnston Jr, J.T. DeWolf and D.F. Mazurek, 2014. Mechanics of Materials. 7th Edn., McGraw-Hill Education, New York, USA., ISBN:978-0073398235, Pages: 896.

Beer, F.P., E.R. Johnston, D.F. Mazurek, P.J. Cornwell and S. Sanghi et al., 2013. Vector Mechanics for Engineers: Statics \& Dynamics. 10th Edn., McGraw Hill Education, New York, USA., ISBN: 978-1-25-906291-9.

Benavides, J.E.H., D.E.E. Corredor, R.J. Moreno, R.D. Hernandez and D.H. Alfonso, 2018. Analysis of friction systems on shafts for engineering applications. Intl. J. Appl. Eng. Res., 13: 8871-8881. 
Deitel, P.J. and H.M. Deitel, 2012. Java How to Program. 9th Edn., Pearson Education Inc., Boston, Massachusetts, USA., ISBN-13:978-0-13-257566-9, Pages: 1535.

Evans, S.P., W.C.H. Parr, P.D. Clausen, A. Jones and S. Wroe, 2012. Finite element analysis of a micromechanical model of bone and a new 3D approach to validation. J. Biomech., 45: 2702-2705.

Norton, R.L., 2011. Machine Design: An Integrated Approach. 4th Edn., Pearson, Mexico, ISBN: 9780131384385, Pages: 1055.
Ram, A., 1997. Fundamentals of Polymer Engineering. 1 st Edn., Springer, New York, USA., ISBN: 978-0-306-45726-5, Pages: 237.

Shariatee, M., A. Akbarzadeh, A. Mousavi and S. Alimardani, 2014. Design of an economical SCARA robot for industrial applications. Proceedings of the 2014 2nd RSI/ISM International Conference on Robotics and Mechatronics (ICRoM), October 15-17, 2014, EEE, Tehran, Iran, ISBN:978-1-4799-6743-8, pp: 534-539. 